\title{
Gaming for health across various areas of life
}

$\begin{array}{ccc}\text { Mika } & \text { Paula Ailio }{ }^{1} & \text { Chrisna } \\ \text { Luimula } & { }^{1} \text { Turku University } & \text { Botha- }^{1,2} \\ { }^{1} \text { Turku University } & \text { of Applied } & \text { Ravyse } \\ \text { of Applied } & \text { Sciences } & { }^{1,2} \text { North-West } \\ \text { Sciences, } & \underline{\text { paula.ailio@turku }} & \text { University, } \\ \text { Futuristic } & \underline{\text { amk.fi }} & \text { PHASREC } \\ \text { Technologies } & & \text { South Africa } \\ \underline{\text { mika.luimula@tur }} & & \underline{\text { chrisna.botha@n }} \\ \underline{\text { kuamk.fi }} & & \underline{\text { wu.ac.za }}\end{array}$

\author{
Niina \\ Katajapuu $^{1,3}$ \\ ${ }^{3}$ University of \\ Jyväskylä \\ niina.katajapuu@t \\ urkuamk.fi \\ Raija \\ Korpelainen ${ }^{4}$ \\ ${ }^{4}$ University of \\ Oulu, Finland, \\ Center for Life \\ Course Health \\ Research and \\ Oulu Deaconess \\ Institute \\ $\underline{\text { raija.korpelainen }}$
}

Ari Heinonen ${ }^{3}$

${ }^{3}$ University of

Jyväskylä Faculty

of Sport and

Health Sciences

ari.o.heinonen@j yu.fi

\author{
Timo Jämsä ${ }^{5}$ \\ ${ }^{5}$ University of \\ Oulu, Finland, \\ Medical Physics, \\ Imaging and \\ Technology, and \\ Oulu University \\ Hospital \\ timo.jamsa@oulu
} fi

\begin{abstract}
Lack of physical activity is mostly addressed by implementing programs to promote physical activity but seeing as the major cause for physical inactivity is that of technology. Few studies used the approach to use the very barrier as $s$ mean to try and educate and breed good habits. This paper outlines the design and development of a project that will us various environments, home, gym and outdoors to promote physical activity by means of technology and more specifically games.
\end{abstract} games

Keywords—exergames, physical activity, rehabilitation, serious

\section{INTRODUCTION}

The value of exercise to improve quality of life and prevention of disease has been noted years ago by Hippocrates: "Let food be thy medicine and medicine be thy food". Nothing about the fact that participation in regular physical activity (PA) has a positive effect on quality of life and reduces risk for cancer, non-communicable disease (NCDs) and other lifestyle related conditions has changed over the years $[1,2]$. Yet we see a rise in health care costs related to these conditions [3-5]. The World Health Organization (WHO) prioritize the increase of participation in PA $[1,2]$, as a method to decrease the risk for NCD and cancer. Physical activity however is also used in various fields of rehabilitation. The most well-known are musculoskeletal, cardiac, pulmonary and neurological rehabilitation [1, 6, 7] In recent years PA is also used to improve quality of life in cancer survivors and even those living with terminal disease [8,9]. PA is also used in the prevention of fall risk and improvement in functional ability in elderly $[7,10]$. Various studies also show that PA participation as means of rehabilitation after injury or disease does not just increase quality of life but also activities of daily living [7, 10]. Furthermore, the world's older population continues to grow at an unprecedented rate. Today, 8.5 percent of people worldwide (617 million) are aged 65 and over [11]. People are living longer, but that does not mean that they are living healthier. The increase in our aging population presents many opportunities but also several public health challenges that need to be prepared for.

In Finland the statistics of aging population reflect that of the rest of the world with projections of it increasing by more than $50 \%$ over the next 40 years.

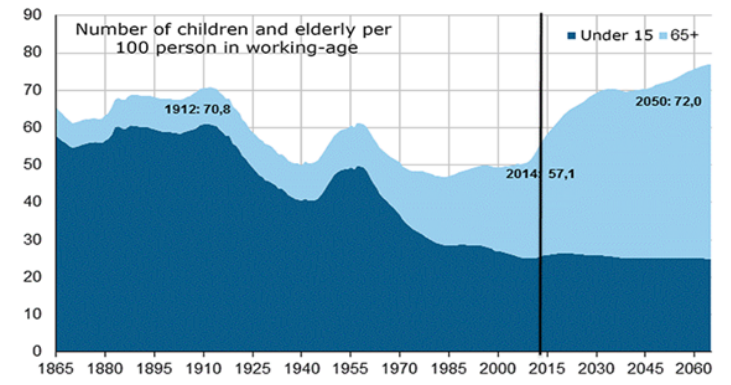

Fig. 1. Demographic dependency ratio in Finland in 1865-2014 and projection for 2015-2050 (Official Statistics of Finland, 2015)

Even though PA will not decrease the rapid growth of ageing population, it can most definitely increase their quality of life and reduce their risk factors for NCDs, which will result in reduced health care costs $[4,12,13]$.

Despite the increased health risks and the health preservation modality of PA, the majority of people in Finland do not participate in PA at the recommended levels [14]. When looking at the programs to increase PA it shows that all of this focus mainly on improvement of physical activity but not changing of sedentary behavior[15]. One of the key factors that increase sedentary behavior is technology. This has led many researchers to develop innovative PA interventions [15], which might be the solution to combat physical inactivity in a technology driven society [16].

\section{BACKGROUND}

Digitalized healthcare service market globally (mobile Health, mHealth) was at $\$ 179.6$ billion in 2016 , according to Transparency Market Research [17]. Growth in this market is predicted to increase at a CAGR of $13.4 \%$ between 2017 and 2025 , reaching $\$ 536.6$ billion by the end of 2025 . Over the next few years, TMR reports that the market will be supported by technology advancements in the medical and healthcare infrastructure[17].

When it comes to saving money mHealth could potentially save a total of $€ 99$ billion in healthcare costs in the EU. Wellness and prevention would be the largest saving (€69 
billion) and treatment/monitoring ( $€ 32$ billion) when taking the costs of the workforce needed to support mHealth into account (€6.2 billion) [18]. However, adoption of these emerging technologies in the public health sector, while promising, will require a high level of organization and management across the various health care sectors to guarantee that the true benefits of improved healthcare can be achieved and sustained.

In Finland, the average cost of an elderly person living in an elderly care home is about 4400 euros per month and in a health-care center about 6200 euros per month [19]. Good physical functioning and ability to live at home is key factor in reducing these costs. With research supporting that participation in physical activity will increase activities of daily living the use of mHealth becomes a real priority.

Although Finland has traditionally been in the forefront of digital and mobile innovations, the digitalized services in healthcare are fragmented, small, and poor in usability, they have interoperability challenges and inappropriate technological platforms [19]. However, with several successful trials and experiments that have taken place already, the fully digitalized distance services are possible to execute in Finland with sufficient coordination and ecosystem of operators with a common understanding of the power of digitalized services. Currently no digital rehabilitation is offered in healthcare, only in fragmented parts and in isolation [19]. Still, several reasons would speak of their increased use, such as the rapidly increasing proportion of elderly in societies which require requires solid alternative to labor intensive and expensive healthcare solutions. The older generation in Finland today are already well familiar with ICT use and even with digital and traditional gaming [20]. The barriers for using digital services will diminish further since future generations are digitally native and used to playing rather than following current traditional treatment and rehabilitation paths [20]. Therefore, implementing digital solutions even in an ageing population will be worthwhile.

One of the main streams in this research planning was "exergames as medicine" as an approach. Previous experience has taught us that we need to show not only the impact of the games, but also whether it is safe to play [21]. This paper gives a snapshot view of the development project Business Ecosystem for Effective Exergaming (BEE) that will pull these different innovations together across various areas of life. This project is a joint interest area between academic and business world. The purpose is to improve health and wellbeing of the person using exergames as well as empower the related businesses.

\section{ARCHITECTURE}

The BEE project is divided into several thematic environments and management parts; home environment, gym environment and outdoor environment as well as entertainment. Various different research activities and evaluations are taking place in each of these. Figure 2 outlines the connections and links between the research areas and gamified environments. Digitalized rehabilitation possibilities are experimented in different environments, such as home, walking outside or at an elderly service home or gym environment. A motivation and reward flow are also illustrated, as it is possible to integrate into different exergaming environments.

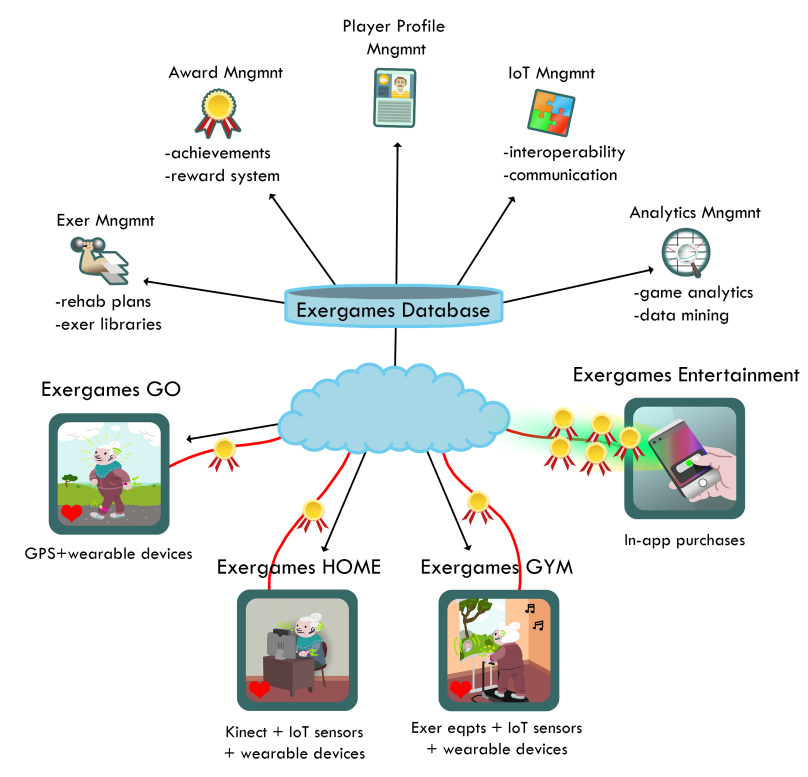

Fig. 2. Snapshot view of the integration

\section{A. Home environment}

The games are focused on digital physical therapy. The goal is to develop a generic exergaming concept (exercises can be chosen by dragging and dropping, same exergame concepts can be used in various exercises). Knee rehabilitation was chosen as primary application areas. Knee rehabilitation supports also our collaboration with partners in China. The HOME environment is developed as a general platform for various other applications as well. Exergames HOME environment is based on Kinect-based motion detection as user interaction. Previous research in this area indicates that the usability of gamified solutions should not be complex to the point that it frustrates the player, thereby hindering the rehabilitation or goal of the exercise $[22,23]$. Thus, high usability was a main focus in the development of our games. Furthermore, the games are packaged together and scheduled week by week to ensure that the patient follows the progressive program for the duration of 16 weeks. We are making use of collaborative work with PhysioTools Ltd, a market leader with around 2400+ exercises in their library with an innovative PTMomentum application developed by GoodLife Technology that fits perfectly to the existing rehabilitation process. PT Momentum has been tested and was well received by therapists and their clients. The app has brought professionals new possibilities and strengthened their clients' positive treatment experience."

We are building on the above-mentioned approach and proceed by digitizing physical therapy utilizing artificial intelligence, motion detection sensors, gamified solutions etc. 


\section{B. Outdoor environment}

The purpose of Exergames GO environment is to get people moving and outside by means of an interactive game that are mainly using GPS and augmented reality in user interaction. One of the motivations for this environment was the success that was reported on Pokemon GO. However, in this case user interaction methods will be expanded through wearable devices. We are working with market leaders in health monitoring such as Suunto, Polar, and FirstBeat and leveraging their expertise to bridge the sensory modalities of IoT sensors and game analytics [24]. This development is work in progress.

\section{Gym environment}

Exergames GYM environment has not been developed yet. It will mainly make use of motion detection in user interaction in GYM environment, enhanced by sensors and wearable devices. Exercise equipment will also be included in the GYM environment testing, where exercising on equipment is motivated through games and performance measured by motion detection. This environment is in its planning phases. The project has partnered with the company David Health Solutions which will make use of gaming elements to bring fitness to the users in a fun and immersive way, making use of the already interactive technologies of David Health.

\section{METHODS}

The participatory action research (PAR) strategy is followed in the development of these three environments. This approach is based on continuing cycles of reflection, data collection and further development actions that aim to improve the feasibility and acceptability of the solutions. We aim to generate a comprehensive solution for digital rehabilitation using co-creation with various technology providers, exergaming professionals and service providers together with end users. With the co-creation principle, the involvement of end-users ensures that the technologies and solutions are acceptable. Rehabilitation experts will be involved in the selection, application and verification stages of the created digitizes rehabilitation services. Co-operation with experts and industry partners will enable new interactions across the whole ecosystem. This research and development strategy is described in Figure 3.

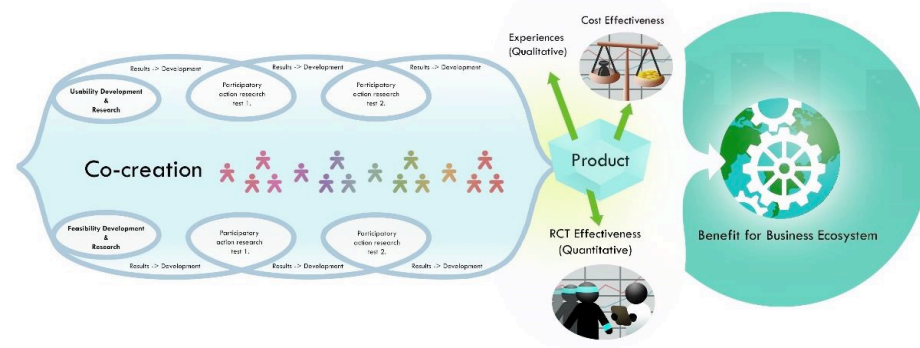

Fig. 3. PAR design in this project

\section{A. Technical methodology}

The core of the analytics is to support patients with realtime instructions and two-way feedback, and to learn to use the digital gamified applications. The Exercise management integration consists of joint rehab plans, conversions thereof into digital format, and select exercises for gamified applications. Remote instruction and tutorials are managed on the digital platform.

The award mechanic is designed to motivate the patient to perform the exercises. Exercising and performing rehabilitation movements should be made fun and engaging and reward is an extrinsic motivator that may play a role in achieving this.

Data management will follow the rehabilitation and generate visualization of the progress in exercises. Feedback reports to users and professionals and potential alarms are generated in the Analytics management environment. Player profiles are validated, based on the exercise performances, and the analytics management determines the next exercise baseline. Exercises will be categorized by difficulty levels, rehabilitation aims and user experience level.

\section{Prelimanary Results}

These games are all a continuum for previous projects Gamified Solutions in Healthcare (GSH) [21] and GASEL [25] projects, both funded by Tekes. In GSH, we had totally 271 test subjects, mainly elderly people from Finland, Japan, and Singapore. In GSH, our focus was not yet on long term tests for effectiveness but more about feasibility, usability, cultural differences, motivational factors etc. One of the pilot tests were at two senior activity centers in Singapore in 2016. The pilot experiment showed that elderly people enjoyed the gamified therapeutic exercise and that the exercise adherence was very high. It suggests that these novel digital therapeutic exercises have a motivation factor and are enjoyed by the user [23]. A second pilot test was also carried out in Finland, where Japanese exergame called RecReha was tested with 12 elderly. Results show that even though the games were fun to use and worked well there was a risk for elderly in some of the jumping movements in the games that need to be addressed [22].

The information gathered by GSH and GASEL projects are being used to ensure that the games meet the expectations by the end users and health workers in different countries involved in BEE project.

\section{RELEVANCE TO COGNITIVE INFOCOMMUNICATION}

The definition of CogInfoCom was accepted in 2010 [24] as follows: "Cognitive infocommunications (CogInfoCom) investigates the link between the research areas of infocommunications and cognitive sciences, as well as the various engineering applications which have emerged as a synergic combination of these sciences." This definition is further unpacked by Baranyi and Csapo [24] and makes the link that any hardware or software that can store information and allow users to interact with this information would be considered as an infocommunication system. The whole BEE project is based on gathering data from the user; physiological 
data ie. heart rate and squat height; position data; speed; distance etc. This data will give feedback to the user about their physical activity in a digital metric. This metric will make the user cognitively aware of their PA progress. As they continue using the related software, it will guide them how to modify their use of the software when needed. This is based on the information given by the software data feedback. This type of info-feedback-replay will happen throughout all phases of the project. Furthermore throughout the different aspects of the various applications used in this project both sensory sharing and sensory bridging concepts are being used.

\section{DISCUSSION}

This project develops exergaming solutions for three different environments. The games will be nested together in a health application/site where one will be able to choose one of the three environment in which he/she would want to exercise. Any activity performed in one of the environments will be linked to one database that will show reps, sets etc. This will also provide valuable information for both the player and the health professional to track a patient's fitness and recovery.

Currently there are various state of the art applications that make use of some sort of CogInfoCom aspects in order to drive their application and aiming to provide a more enjoyable user experience. However, the approach presented here is novel since we are taking all these various applications that make use of a number of different devices, software applications and other "smart technology equipment", and merge them into one business ecosystem, in which the users can access their results at any time, use them to set goals and choose what mode of training they want to use without having to worry about data transfer. This type of approach can really provide valuable information for both researchers but also health care workers that look after the health of the users. This can help them to give support, motivate and manage their clients or patients better.

The preliminary feedback obtained from rehabilitation specialists and doctors in a sample test done on the home environment in China suggests that these games has the potential to really enhance the rehabilitation process, and health care professionals are excited about implementing these not only for research but also as part of their rehabilitation process.

\section{ACKNOWLEDGMENT}

This study is part of the Business Ecosystems for Effective Exergaming (BEE) project, funded by Business Finland (grant 6057/31/2016). The authors acknowledge Adesante Ltd, David Health Solutions Ltd, eHoiva Ltd, GoodLife Technology Ltd, Lingsoft Ltd, PhysioTools Ltd, PN Turku Ltd, SE Innovations Ltd, and Suunto Ltd for their support.

\section{REFERENCES}

C. Foster, T. Shilton, L. Westerman, J. Varney, and F. Bull, "World Health Organisation to develop global action plan to promote physical activity: time for action," ed: BMJ Publishing Group Ltd and British Association of Sport and Exercise Medicine, 2017.
[2] A. R. Varela et al., "Worldwide Surveillance, Policy, and Research on Physical Activity and Health: The Global Observatory for Physical Activity," Journal of Physical Activity and Health, vol. 14, no. 9, pp. 701-709, 2017.

[3] B. Stewart and C. P. Wild, "World cancer report 2014," Health, 2017.

[4] A. L. Cradock et al., "Using cost-effectiveness analysis to prioritize policy and programmatic approaches to physical activity promotion and obesity prevention in childhood," Preventive medicine, vol. 95, pp. S17-S27, 2017.

[5] K. Abu-Omar, A. Rütten, I. Burlacu, V. Schätzlein, S. Messing, and M. Suhrcke, "The cost-effectiveness of physical activity interventions: A systematic review of reviews," Preventive medicine reports, vol. 8, pp. 72-78, 2017.

[6] S. M. Parry et al., "Factors influencing physical activity and rehabilitation in survivors of critical illness: a systematic review of quantitative and qualitative studies," Intensive care medicine, vol. 43, no. 4, pp. 531-542, 2017.

[7] C. F. Nooijen, H. J. Stam, T. Sluis, L. Valent, J. Twisk, and R. J. van den Berg-Emons, "A behavioral intervention promoting physical activity in people with subacute spinal cord injury: secondary effects on health, social participation and quality of life," Clinical rehabilitation, vol. 31, no. 6, pp. 772-780, 2017.

[8] S. Krebs, A. Berling-Ernst, and M. Halle, "Physical Activity and Cancer," Sportverletzung Sportschaden: Organ der Gesellschaft fur Orthopadisch-Traumatologische Sportmedizin, 2017.

[9] N. M. Gell, K. W. Grover, M. Humble, M. Sexton, and K. Dittus, "Efficacy, feasibility, and acceptability of a novel technologybased intervention to support physical activity in cancer survivors," Supportive Care in Cancer, vol. 25, no. 4, pp. 1291-1300, 2017.

[10] M. Imanishi, H. Tomohisa, and K. Higaki, "Impact of continuous in-home rehabilitation on quality of life and activities of daily living in elderly clients over 1 year," Geriatrics \& gerontology international, vol. 17, no. 11, pp. 1866-1872, 2017.

[11] NIH. (29 May). World's older population grows dramatically. Available: $\quad$ https://www.nih.gov/news-events/newsreleases/worlds-older-population-grows-dramatically

[12] C. Lanhers et al., "Long-term cost reduction of routine medications following a residential programme combining physical activity and nutrition in the treatment of type 2 diabetes: a prospective cohort study," BMJ open, vol. 7, no. 4, p. e013763, 2017.

[13] D. Ding, T. Kolbe-Alexander, B. Nguyen, P. T. Katzmarzyk, M. Pratt, and K. D. Lawson, "The economic burden of physical inactivity: a systematic review and critical appraisal," Br J Sports Med, pp. bjsports-2016-097385, 2017.

[14] J. A. Bennie et al., "Self-reported health-enhancing physical activity recommendation adherence among 64,380 finnish adults," Scandinavian journal of medicine \& science in sports, vol. 27, no. 12, pp. 1842-1853, 2017.

[15] B. A. Lewis, M. A. Napolitano, M. P. Buman, D. M. Williams, and C. R. Nigg, "Future directions in physical activity intervention research: expanding our focus to sedentary behaviors, technology, and dissemination," Journal of behavioral medicine, vol. 40, no. 1, pp. 112-126, 2017.

[16] O. Lopez-Fernandez, N. Männikkö, M. Kääriäinen, M. D. Griffiths, and D. J. Kuss, "Mobile gaming and problematic smartphone use: A comparative study between Belgium and Finland," Journal of behavioral addictions, pp. 1-12, 2018.

[17] TMR. (July 2015, 28 May). mHealth Services Market Driven at 23.9\% CAGR by Demand for Homecare. Available: https://www.transparencymarketresearch.com/pressrelease/mobilehealth-market.htm

[18] GSMA, " Socio-economic impact of mHealth," 2013.

[19] A. Salminen, S. Hiekkala, and J. Stenberg, "Etäkuntoutus," 2016.

[20] K. Sato, K. Kuroki, S. Saiki, and R. Nagatomi, "Improving walking, muscle strength, and balance in the elderly with an exergame using Kinect: A randomized controlled trial," Games for health journal, vol. 4, no. 3, pp. 161-167, 2015.

[21] M. Luimula, P. Pitkäkangas, T. Saarenpää, N. B. Trygg, and A. Pyae, "STUDENTS'ROLE IN GAMIFIED SOLUTIONS IN HEALTHCARE RDI PROJECT," in The 12th International CDIO Conference, vol. 5, p. 219. 
[22] A. Nakai, M. Luimula, S. Hongo, and H. Vuola, "Evaluating a game motion-based control by using kansei engineering knowledge," in Cognitive Infocommunications (CogInfoCom), 2013 IEEE 4th International Conference on, 2013, pp. 139-144: IEEE.

[23] A. Pyae, M. Luimula, and J. Smed, "Pre-studies on Using Digital Games for the Elderly's Physical Activities," in International Conference on Well-Being in the Information Society, 2016, pp. 82-96: Springer.

[24] P. Baranyi and A. Csapo, "Definition and synergies of cognitive infocommunications," Acta Polytechnica Hungarica, vol. 9, no. 1, pp. $67-83,2012$.

[25] N. S. Keranen et al., "Use of Information and Communication Technologies Among Older People With and Without Frailty: A Population-Based Survey," (in eng), J Med Internet Res, vol. 19, no. 2, p. e29, Feb 142017. 